\title{
FOURIER TRANSFORM INFRARED SPECTROSCOPY SPECTROSCOPIC STUDIES IN EMBELIA RIBES BURM. F.: A VULNERABLE MEDICINAL PLANT
}

\author{
VIDYA KAMBLE, NIKHIL GAIKWAD* \\ Department of Botany, Shivaji University, Kolhapur - 416 004, Maharashtra, India. *Email: nbgaikwadsuk@gmail.com
}

Received: 01 July 2016, Revised and Accepted: 26 August 2016

\section{ABSTRACT}

Objective: The present study was aimed to identify the functional group present in the crude powder and various solvent extracts of Embelia ribes Burm. f. stem, leaves, and berries through Fourier transform infrared (FTIR) spectroscopy.

Methods: Different plant parts of E. ribes were collected shade dried, powdered, and extracted in methanol, ethanol, and petroleum ether. These extracts were used to detect the characteristic peak values and their functional groups using FTIR method on a OMNI sampler attenuated total reflectance accessory on a JASCO FTIR spectrophotometer (FTIR-4600).

Results: The crude powder of E. ribes leaves, stem, and berries FTIR analysis confirmed the presence of amino acids, amide, alkanes, carboxylic acids, alcohols, esters, ethers, aromatics, aliphatic amines, phenols, aldehyde, ketones, fluorides, halogen, alkyl halides, and nitro compound. The dry methanolic and ethanolic extracts of E. ribes leaves, stem, and berries FTIR analysis results proved the presence of alcohols, p-substituted alcohols or phenols, phenols, alkanes, alkynes, alkenes, aldehyde, ester, ether, aliphatic amines, carboxylic acids, aromatics, ketones, disulphide, alkyl halides, halogen, and nitro compounds, whereas dry petroleum ether extract shown the presence of amide, alkanes, carboxylic acids, alcohols, p-substituted alcohols or phenols, esters, aromatics, aldehyde, ketones, aryl disulphide, aliphatic amines, aliphatic compound, alkyl halides, and nitro compounds, respectively.

Conclusion: The results of the present study produced the FTIR spectrum profile for the vulnerable medicinally important plant $E$. ribes Burm. f.

Keywords: Embelia ribes Burm. f., Fourier transform infrared spectroscopy, Spectroscopy, Functional groups.

(C) 2016 The Authors. Published by Innovare Academic Sciences Pvt Ltd. This is an open access article under the CC BY license (http://creativecommons. org/licenses/by/4. 0/) DOI: http://dx.doi.org/10.22159/ajpcr.2016.v9s3.13804

\section{INTRODUCTION}

Fourier transform infrared (FTIR) spectrometry measures the vibrations of bonds within chemical functional groups and generates a spectrum that can be regarded as a biochemical or metabolic "fingerprint" of the sample. By attaining IR spectra from plant samples, it might possible to detect the minor changes of primary and secondary metabolites $[1,2]$. At present, particularly in phytochemistry, FTIR has been exercised to identify the concrete structure of certain plant secondary metabolites $[3,4]$.

FTIR is one of the most widely used methods to identify the chemical constituents and elucidate the compound structures to propose in medicinal purposes $[5,6]$. Previous researchers carried out the FTIR to notice the minor changes of primary and secondary metabolites $[1,2]$ and to recognize the concrete structure of certain plant secondary metabolites [7]. The characteristics functional groups are responsible for the medicinal properties of plant are confirmed by FTIR analysis [8] Embelia ribes Burm. f. locally known as false black pepper or vidanga belongs to family Myrsinaceae. It is an important medicinal dioecious woody climber, sparsely distributed in the evergreen to moist deciduous forests of the Western Ghats [9]. It is listed in the "priority species list" for cultivation by the National Medicinal Plant Board and the Maharashtra State Horticulture and Medicinal Plant Board [10]. It is used as an ingredient in about 75 traditional ayurvedic drug formulations [11]. The fruit of the E. ribes Burm. f. plant has been used to treat fever, inflammatory diseases, and a variety of gastrointestinal ailments for thousands of years [12]. More than four decades ago, the active component from this plant was isolated and named embelin [13] and later synthesizes [14]. Embelin has been shown to have antitumor, anti-inflammatory, and analgesic properties [15]. From pharmaceutical point of view, E. ribes contains embelin, fatty ingredients, quercitol, alkaloid christembine, tannins, and volatile oils.
FTIR provides biochemical profiles containing overlapping signals from a majority of the compounds that are present when whole cells are surely analyzed [16]. In the present investigation, crude powder and solvent extracts of root, stem, and berries of $E$. ribes were analyzed. With this background, the present study was aimed to report the main functional components of the present in leaves, stem, and berries of E. ribes using Fourier transform infrared spectroscopy (FTIR) spectrometry.

\section{METHODS}

Collection and processing of plant material

Plant material of E. ribes was collected from Devimane Ghats, TalSirsi, District - Uttara Kannada, Karnataka, India (GPS-N 14²31.278', E $\left.074^{\circ} 32.849^{\prime}\right)$. The plant materials were identified at the Department of Botany, Shivaji University, Kolhapur. Voucher specimens were prepared and deposited in the herbarium of the Department of Botany, Shivaji University, Kolhapur. The leaves, stem, and berries were separately shade dried, cut into small pieces, and fine powder was prepared by grinding. Powdered material was stored in an airtight container for further use.

\section{Preparation of extract}

The powdered plant parts (leaves, stem, and berries) $10 \mathrm{~g}$ each were extracted in $100 \mathrm{ml}$ of methanol, ethanol, and petroleum ether with continuous shaking on mechanical shaker for $24 / \mathrm{hrs}$ at room temperature. The extracts were then filtered through Whatmann No. 1 filter paper and stored in airtight vials for refrigeration. Stored extract was used for further analysis.

\section{FTIR spectroscopic analysis}

All spectra were obtained with the aid of OMNI sampler attenuated total reflectance accessory on a JASCO FTIR spectrophotometer (FTIR-4600) followed by previous methods with some modifications. A dry powder 
of leaves, stem, and berries was encapsulated in $\mathrm{KBr}$ pellet, to prepare translucent sample discs. Small amount of each plant part sample extract of different solvents was, respectively, placed directly on the germanium piece of the infrared spectrometer with constant pressure applied. Data of infrared absorbance were collected over the wave number ranged from $4000 / \mathrm{cm}$ to $650 / \mathrm{cm}$. The reference spectra were acquired from the cleaned blank crystal before the presentation of each sample replicate. All spectra were collected with a resolution of 4.0-1.0 cm and to improve the signal-to-noise ratio. Samples were run in triplicates. The FTIR spectrum of all samples was analyzed on the basis of peak values in the region of infrared radiation.

\section{RESULTS AND DISCUSSION}

The FTIR spectrum was used to identify the functional groups of the active components in plant samples based on the peak value in the region of infrared radiation [12]. The crude powder and solvent extract of stem, leaves, and berries of $E$. ribes gave the following characteristic absorption peaks as represented in Figs. 1-4 and Tables 1-4. The FTIR spectroscopy is proved to be a reliable and sensitive method for detection of biomolecular composition [13]. The absorption spectra of crude powder of $E$. ribes stem, leaves, and berries are shown in Fig. 1 and Table 1 . The results of $E$. ribes crude stem powder FTIR analysis confirmed the presence of phenol at peak of $3775.23 / \mathrm{cm}$. The peak at $3305.54 / \mathrm{cm}$ represents the presence of amine and amide as functional group. The peak at 2918.20 and $2854.03 / \mathrm{cm}$ confirms the presence of alkanes.

The peak at $1733.78 / \mathrm{cmrepresents}$ the presence of aldehyde and ketone. The peak at 1605.32, 1510.87, and 1433.68/cm indicated the presence of amino acid, nitro compound, and aromatic functional group, respectively. The peak at 1363.50, 1324.20, and 1233.79/cm confirms the presence of alkane, aldehyde, fluoride, nitro, and alkyl halide group, respectively. The remaining peak at $1022.65,822.94$, 764.05 , and $662.95 / \mathrm{cm}$ indicated the presence of alcohol, aliphatic amines, aromatic compound, primary or secondary amines, and halogen group, respectively. In case of crude leaves powder, the peak observed at $3779.21,3691.45$, and $3282.84 / \mathrm{cm}$ represented the presence of phenol, amide, primary, or secondary amines as functional group, respectively. The peak at 2915.55, 2849.86, 2349.27, 1606.20, and $1443.36 / \mathrm{cm}$ showed the alkanes, carboxylic acid, alkenes, amino acid, and aromatic as functional group. The peak at 1364.60, 1314.63, 1233.56 , and $1149.10 / \mathrm{cm}$ indicated the presence of alkanes, nitro compound, fluorides, aliphatic amines, alkyl halide, and ether as a functional group. The remaining peak at 1022.20, 828.21, 715.06, 659.77 , and $594.32 / \mathrm{cm}$ confirms the presence of aliphatic amines, amines, primary or secondary amines, halogen, and alkyl halide as functional group. In case of crude berries powder, the peak observed at $3780.18,3304.76$, and $2918.89 / \mathrm{cm}$ indicated the presence of phenol, amine, amide, and alkanes as functional group, respectively. The peak at $2852.34,1734.22,1607.46,1445.93$, and $1325.32 / \mathrm{cm}$ shown the presence of alkanes, aldehyde, ketone, amino acid, aromatics, and nitro compound as functional group, respectively. The remaining peak at $1193.92,1019.50,762.70,703.02$, and 613.95/cm confirms the presence of functional group, namely, aliphatic amines, aromatic compound, aliphatic compound, and alkyl halide, respectively.

The absorption spectra of methanolic extract of $E$. ribes stem, leaves, and berries are shown in Fig. 2 and Table 2. The methanolic extract of E. ribes stem FTIR analysis confirms the presence of alcohol, amines, and amide at $3342.03 / \mathrm{cm}$ peak value. The peak at 2943.8 and $2831.95 / \mathrm{cm}$ indicated the presence of alkane. The remaining peak at $1613.16,1455.63,1120.44,1020.16$, and $627.716 / \mathrm{cm}$ represents the presence of amino acids, aromatic, ether compound, aliphatic amines, alcohols, alkynes, disulfides, and alkyl halide as a functional group, respectively. In case of methanolic extract of leaves, the peak observed at 3344.93 and $2936.09 / \mathrm{cm}$ shown the presence of alcohol, amines, amides, and alkanes, respectively. The peak at $2832.92 / \mathrm{cm}$ confirms the presence of alkanes and carboxylic acid. The remaining peak at $1644.98,1455.99,1021.12,799.35,635.43$, and $624.323 / \mathrm{cm}$ indicates the presence of alkenes, aromatic, aliphatic amines, alcohols, aromatic compound, aldehyde, halogen, alkyl halide, alkynes, and disulfides as functional group, respectively. The methanolic extract of berries proved

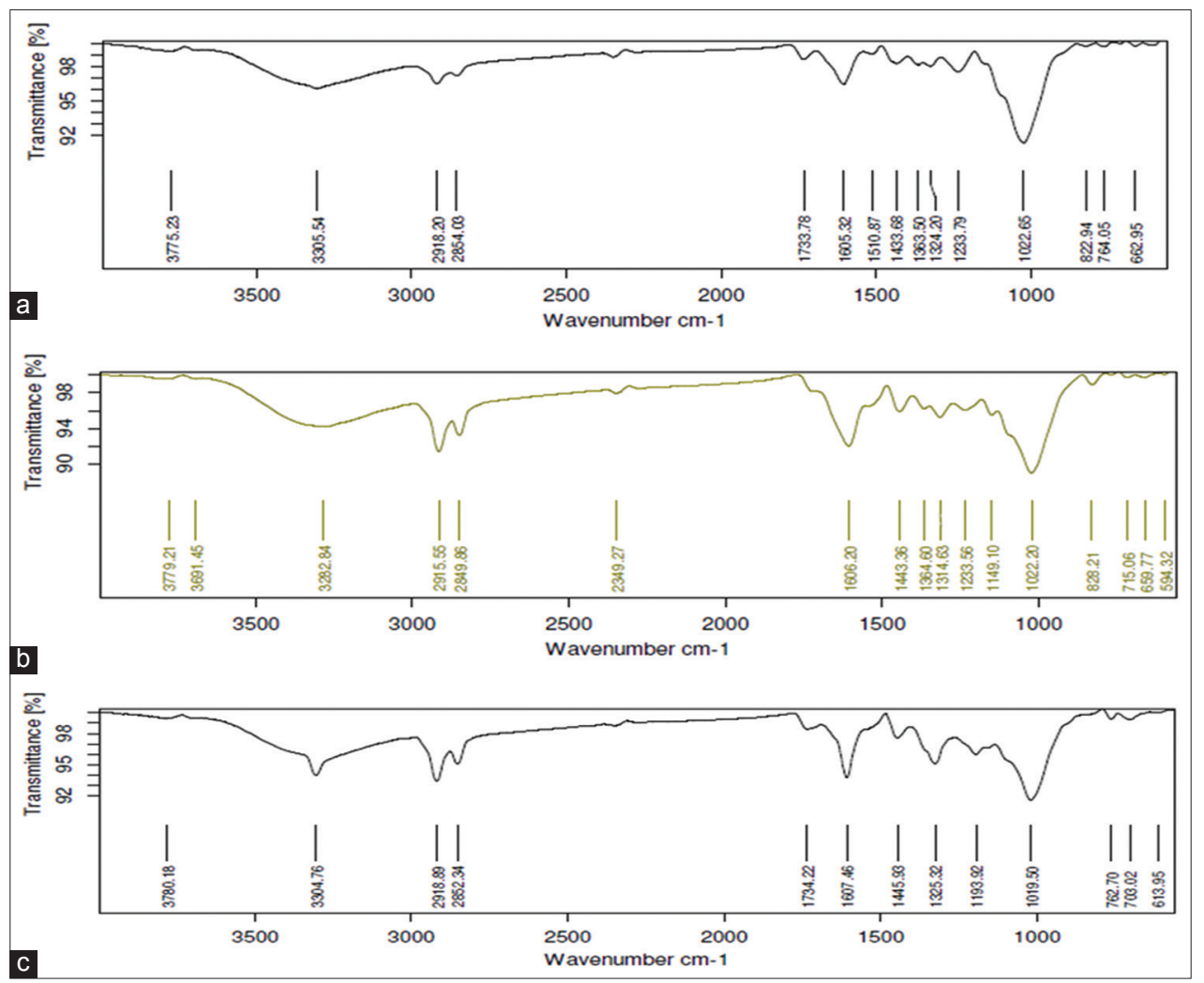

Fig. 1: Fourier transform Infrared spectrum analysis of Embelia ribes crude powder of (a) stem, (b) leaves, (c) berries 


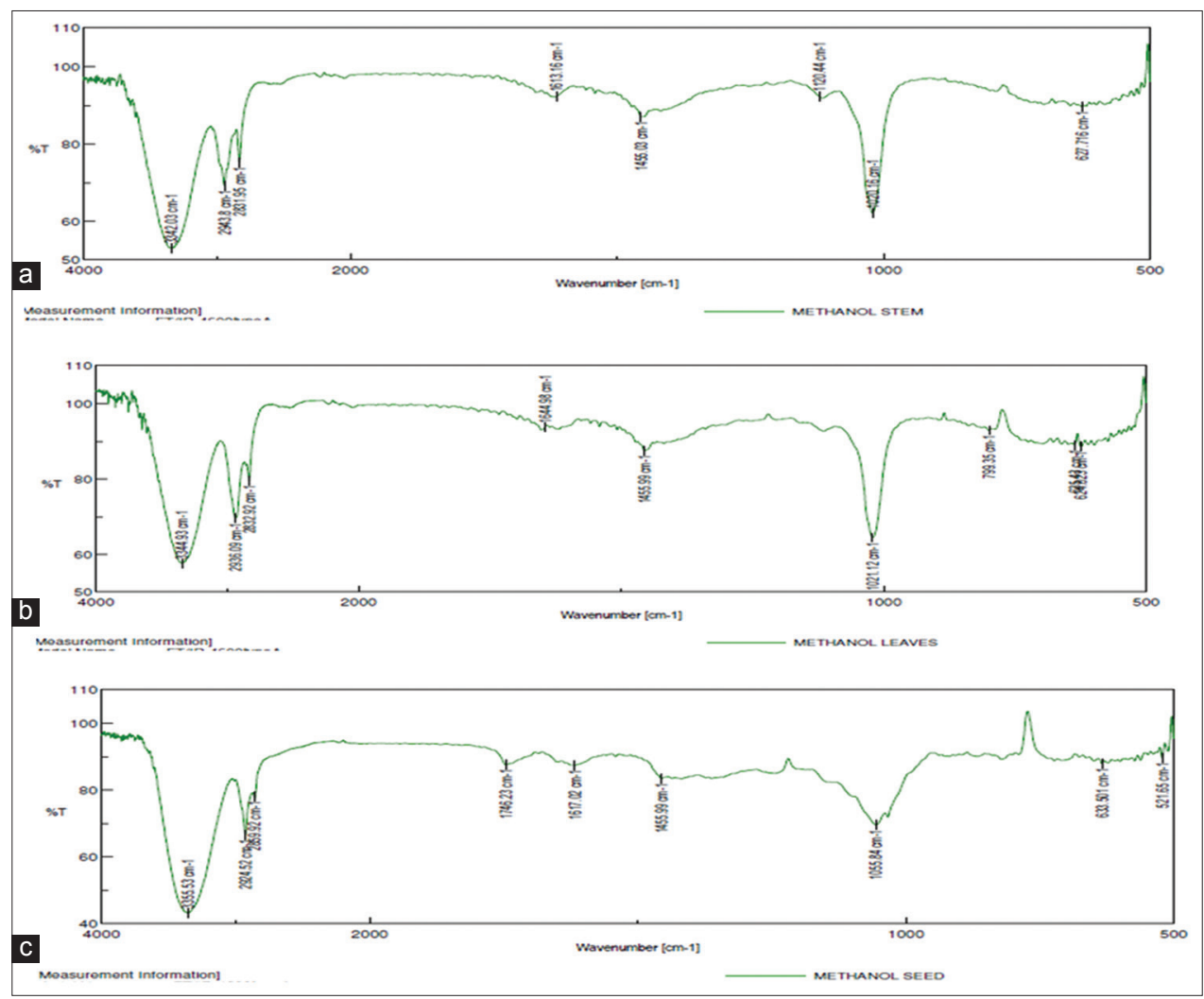

Fig. 2: Fourier transform Infrared spectrum analysis of Embelia ribes methanolic extract of (a) stem, (b) leaves, (c) berries

Table 1: FT-IR peak values and functional groups of crude powder of Embelia ribes

\begin{tabular}{|c|c|c|c|c|c|c|}
\hline \multirow{2}{*}{$\begin{array}{l}\text { Serial } \\
\text { number }\end{array}$} & \multicolumn{6}{|c|}{ Functional groups of the active component in crude powder of Embelia ribes } \\
\hline & $\begin{array}{l}\text { Stem peak } \\
\text { value }\end{array}$ & Functional group & $\begin{array}{l}\text { Leaves } \\
\text { peak value }\end{array}$ & Functional group & $\begin{array}{l}\text { Berries } \\
\text { peak value }\end{array}$ & Functional group \\
\hline 2 & 3305.54 & Amine, amide & 3691.45 & Amide & 3304.76 & Amine, amide \\
\hline 3 & 2918.20 & Alkane & 3282.84 & Primary/secondary amines & 2918.89 & Alkane \\
\hline 4 & 2854.03 & Alkane & 2915.55 & Alkane & 2852.34 & Alkane \\
\hline 5 & 1733.78 & Aldehyde, ketones & 2849.86 & Carboxylic acid, alkane & 1734.22 & Aldehyde, ketone \\
\hline 6 & 1605.32 & Amino acid & 2349.27 & Alkenes & 1607.46 & Amino acid \\
\hline 7 & 1510.87 & Nitro compound, aromatic & 1606.20 & Amino acid & 1445.93 & Aromatic \\
\hline 8 & 1433.68 & Aromatic & 1443.36 & Aromatic, & 1325.32 & Nitro \\
\hline 9 & 1363.50 & Alkanes, aldehyde, fluoride & 1364.60 & Alkanes & 1193.92 & Aliphatic amines \\
\hline 10 & 1324.20 & Nitro & 1314.63 & Alkane, nitro compound & 1019.50 & Aliphatic amines \\
\hline 11 & 1233.79 & Fluoride, alkyl halide & 1233.56 & $\begin{array}{l}\text { Fluorides, aliphatic amines, } \\
\text { alkyl halide }\end{array}$ & 762.70 & Aromatic compound \\
\hline 12 & 1022.65 & Alcohol, aliphatic amines & 1149.10 & Ether & 703.02 & Aliphatic compound \\
\hline 15 & 662.95 & Halogen & 715.06 & Primary/secondary amines & & \\
\hline 16 & & & 659.77 & Halogen & & \\
\hline 17 & & & 594.32 & Alkyl halide, halogen & & \\
\hline
\end{tabular}

FTIR: Fourier transform infrared spectroscopy

the presence of alcohol, amines, amide, and alkane, which shown the major peak at 3355.53, 2924.52, and 2859.92/cm,respectively. The remaining peak at 1746.23, 1617.02, 1455.99, 1055.84, 633.501, and $521.65 / \mathrm{cm}$ indicates the presence of aldehyde, ester, amino acid, alkanes, aliphatic amines, alcohols, carboxylic acid, alkyl halide, and halogen as a functional group, respectively.

The absorption spectra of ethanolic extract of E. ribes stem, leaves, and berries are shown in Fig. 3 and Table 3. The results of E. ribes stem FTIR analysis confirmed the presence of amines, amide, alcohol, alkanes, and carboxylic acid at the peak value of 3354.57 and $2972.73 / \mathrm{cm}$, respectively. The peak at 2884.12, 1379.82, and $1086.69 / \mathrm{cm}$ represents the presence of alkane, alkyl group, and aliphatic amines as functional group, respectively. The remaining peak at $1045.23,879.381,803.206$, and $635.43 / \mathrm{cm}$ confirms the presence of aliphatic amines, primary or secondary amines, p-substituted alcohols or phenols, alkynes, alkyl halide, and disulfide as a functional group, respectively. In case of ethanolic extract of leaves, the peak observed at $3750.87,3649.62$, and $3387.35 / \mathrm{cm}$ confirms the presence of phenols, amide, and alcohol as a functional group, 


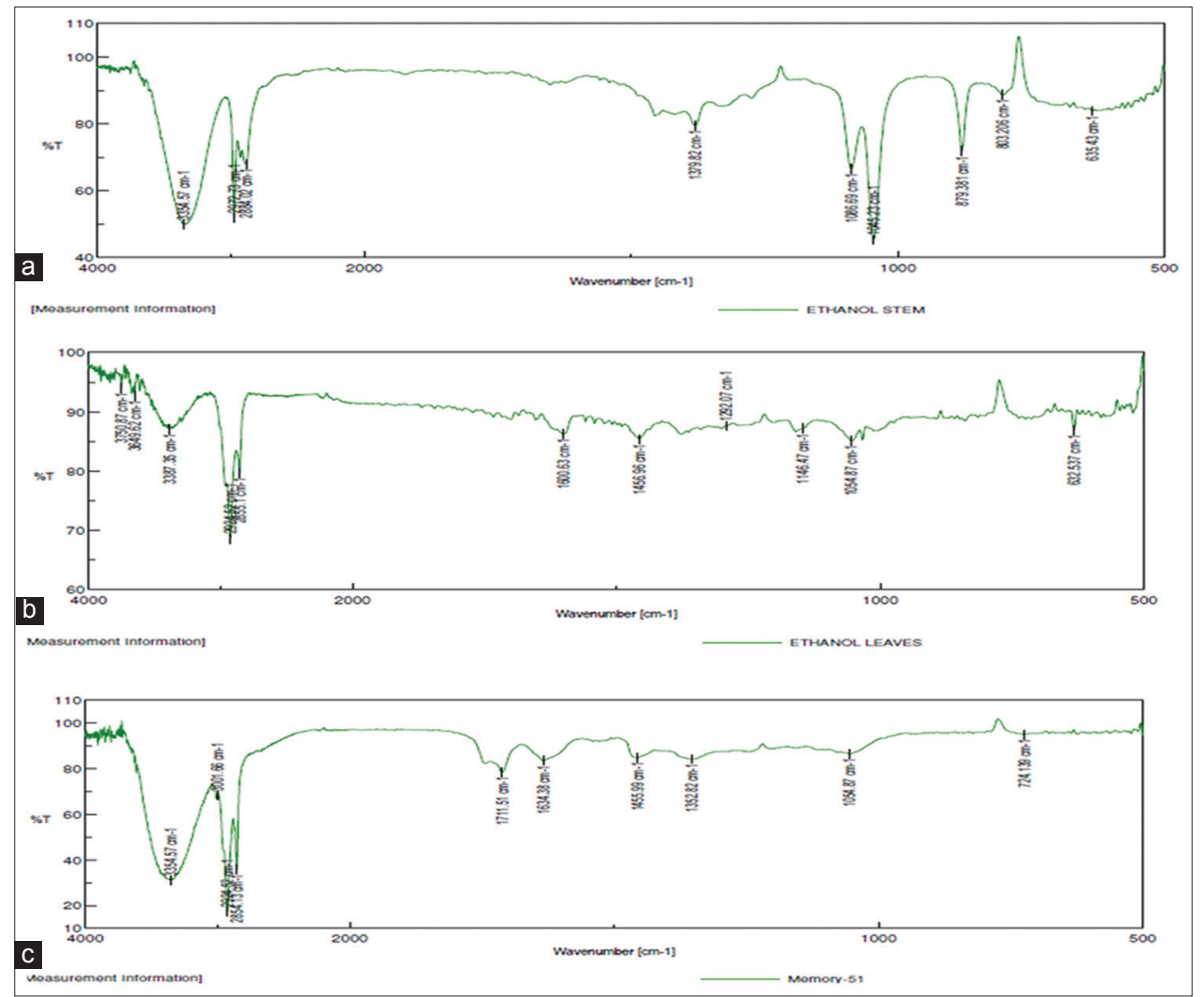

Fig. 3: Fourier transform Infrared spectrum analysis of Embelia ribes ethanolic extract of (a) stem, (b) leaves, (c) berries

Table 2: FTIR peak values and functional groups of methanolic extract of Embelia ribes

\begin{tabular}{|c|c|c|c|c|c|c|}
\hline \multirow{2}{*}{$\begin{array}{l}\text { Serial } \\
\text { number }\end{array}$} & \multicolumn{6}{|c|}{ Functional groups of the active component in methanolic extract Embelia ribes } \\
\hline & $\begin{array}{l}\text { Stem peak } \\
\text { value }\end{array}$ & Functional group & $\begin{array}{l}\text { Leaves } \\
\text { peak value }\end{array}$ & Functional group & $\begin{array}{l}\text { Berries } \\
\text { peak value }\end{array}$ & Functional group \\
\hline 1 & 3342.03 & Alcohol, amines, amides & 3344.93 & Alcohol, amines, amides & 3355.53 & Alcohol, amines, amides \\
\hline 2 & 2943.8 & Alkane & 2936.09 & alkanes & 2924.52 & Alkanes \\
\hline 3 & 2831.95 & Alkane & 2832.92 & Alkanes, carboxylic acids & 2859.92 & Alkanes \\
\hline 4 & 1613.16 & Amino acids & 1644.98 & Alkenes & 1746.23 & Aldehyde, ester \\
\hline 5 & 1455.63 & Aromatic & 1455.99 & Aromatic & 1617.02 & Amino acids \\
\hline 6 & 1120.44 & Ether compound & 1021.12 & Aliphatic amines, alcohols & 1455.99 & Alkanes \\
\hline 7 & 1020.16 & Aliphatic amines, alcohols & 799.35 & $\begin{array}{l}\text { Aromatic compound, aldehyde, } \\
\text { halogen }\end{array}$ & 1055.84 & $\begin{array}{l}\text { Aliphatic amines, alcohols, } \\
\text { carboxylic acids }\end{array}$ \\
\hline 8 & 627.716 & $\begin{array}{l}\text { Alkynes, disulfides, alkyl } \\
\text { halide }\end{array}$ & 635.43 & Alkyl halide & 633.501 & Alkyl halide \\
\hline 9 & & & 624.323 & Alkynes, disulfides, alkyl halide & 521.65 & Halogen, alkyl halide \\
\hline
\end{tabular}

FTIR: Fourier transform infrared spectroscopy

respectively. The peak at 2924.52 and $2855.1 / \mathrm{cm}$ represents the presence of alkanes and aldehyde as a functional group, respectively. The remaining peak at $1600.63,1456.96,1292.07,1146.47,1054.87$ and 632.537 indicates the presence of amino acids, aromatics, alkanes, nitro compound, alkyl halide, carboxylic acid, aliphatic amines, alkynes, and disulfide as a functional group, respectively. The ethanolic extract of $E$. ribes berries shown the presence of amines, amide, alcohol, aldehyde, and alkane at the peak value of 3354.57 2924.52 , and $2854.13 / \mathrm{cm}$, respectively. The peak at 1711.51 , 1634.38 , and $1455.99 / \mathrm{cm}$ indicates the presence of ketones, carboxylic acid, amino acid, aromatics, and alkanes as a functional group, respectively. The remaining peak at 1352.82, 1054.87, and $724.139 / \mathrm{cm}$ confirms the presence of nitro compound, carboxylic acid, aliphatic amines, and aliphatic compound, respectively. The absorption spectra of petroleum ether extract of $E$. ribes stem, leaves, and berries are shown in Fig. 4 and Table 4.
The petroleum ether extract of E. ribes stem FTIR analysis confirms the presence of phenols, amine, amide, alcohol, and alkanes at the peak of $3749.9,3649.62,3309.25$, and $2955.38 / \mathrm{cm}$, respectively. The peak at $2849.31,1731.76$, and $1614.13 / \mathrm{cm}$ shown the presence of alkanes, ketones, aldehyde, and amino acid as a functional group, respectively. The remaining peak at 1462.74, 1376.93, 1190.83, 1081.87, and $728.961 / \mathrm{cm}$ indicates the presence of alkanes, aromatics, nitro compounds, aliphatic amines, p-substituted alcohols, and phenols, respectively. In case of petroleum ether extract of leaves confirms the presence of phenols and alkane at the peak value of 3364.21, 2957.3, and $2923.56 / \mathrm{cm}$, respectively. The peak at 2854.13 and $1705.73 / \mathrm{cm}$ represents the presence of alkanes, aldehyde, ketones, and esters as a functional group, respectively. The remaining peak at 1596.96, 1456.96, $1376.93,1158.04$, and $838.883 / \mathrm{cm}$ indicates the presence of primary amines, aromatics, alkanes, nitro compounds, alkyl halides, and primary or secondary amines as a functional group, respectively. The petroleum 


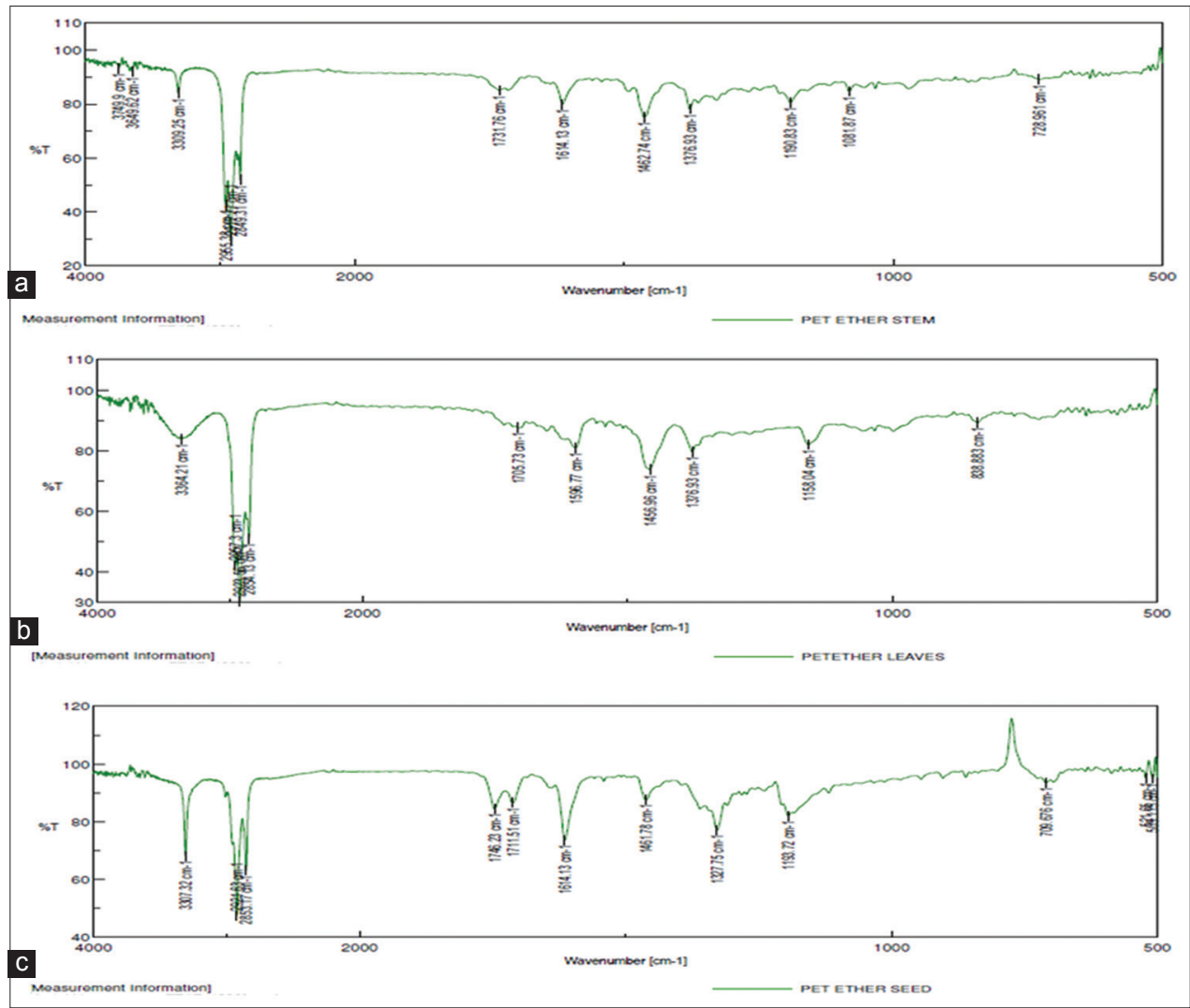

Fig. 4: Fourier transform infrared spectrum analysis of Embelia ribes petroleum ether extract of (a) stem, (b) leaves, (c) berries

Table 3: FTIR peak values and functional groups of ethanolic extract of Embelia ribes

\begin{tabular}{|c|c|c|c|c|c|c|}
\hline \multirow{2}{*}{$\begin{array}{l}\text { Serial } \\
\text { number }\end{array}$} & \multicolumn{6}{|c|}{ Functional groups of the active component in ethanolic extract Embelia ribes } \\
\hline & $\begin{array}{l}\text { Stem peak } \\
\text { value }\end{array}$ & Functional group & $\begin{array}{l}\text { Leaves } \\
\text { peak value }\end{array}$ & Functional group & $\begin{array}{l}\text { Berries } \\
\text { peak value }\end{array}$ & Functional group \\
\hline 1 & 3354.57 & Amines, amide, alcohol & 3750.87 & Phenols & 3354.57 & $\begin{array}{l}\text { Amines, amide, } \\
\text { alcohol }\end{array}$ \\
\hline 2 & 2972.73 & Alkanes, carboxylic acid & 3649.62 & Amide & 2924.52 & Alkanes \\
\hline 3 & 2884.12 & Alkane, alkyl group & 3387.35 & Alcohols, phenols & 2854.13 & Alkane, aldehyde \\
\hline 5 & 1086.69 & Aliphatic amines & 2855.1 & Alkane, aldehyde & 1634.38 & Amino acid \\
\hline 6 & 1045.23 & Aliphatic amines & 1600.63 & Amino acid & 1455.99 & Aromatics, alkanes \\
\hline 7 & 879.381 & Primary, secondary amines & 1456.96 & Aromatics, alkanes & 1352.82 & Nitro compound \\
\hline 8 & 803.206 & p-substituted alcohols/phenols & 1292.07 & Nitro compound, alkyl halide & 1054.87 & $\begin{array}{l}\text { Carboxylic acid, } \\
\text { aliphatic amines }\end{array}$ \\
\hline 9 & 635.43 & $\begin{array}{l}\text { Alkynes, alkyl halide, } \\
\text { disulphide }\end{array}$ & 1146.47 & Alkyl halides & 724.139 & Aliphatic compound \\
\hline 10 & & & 1054.87 & $\begin{array}{l}\text { Carboxylic acid, aliphatic } \\
\text { amines }\end{array}$ & & \\
\hline 11 & & & 632.537 & $\begin{array}{l}\text { Alkynes, alkyl halide, } \\
\text { disulphide }\end{array}$ & & \\
\hline
\end{tabular}

FTIR: Fourier transform infrared spectroscopy

ether extract of berries confirms the presence of alcohol, phenols, alkanes, and esters at the peak value of 3307.32, 2921.63, 2853.17, 1746.23 , and $1711.51 / \mathrm{cm}$, respectively. The remaining peak at 1614.13 , $1461.78,1327.75,1193.72,709.676,521.65$, and $509.115 / \mathrm{cm}$ indicates the presence of amino acid, alkanes, aromatics, nitro compounds, ether, aliphatic compound, alkyl halides, and aryl disulfides as a functional group, respectively.

Using FTIR spectrum, we can confirm the functional constituent's presence in the given parts and extract, identify the medicinal materials from the adulterate, and even evaluate the qualities of medicinal materials [17]. The results of the present FTIR spectroscopy revealed the functional constituents present in the crude powder, methanolic, ethanolic, and petroleum ether extracts of $E$. ribes. It also reveals the similarity and variation between the various parts of $E$. ribes based on the functional group presence and absorption spectrum.

From the spectra, we can see clearly that although they show substantial overlap of each absorption spectrum of various components, each band represents an overall overlap of some characteristic absorption peaks of functional groups in the samples [18]. The crude powder and dry ethanolic extracts of Albizia lebbeck leaves FTIR analysis results proved the presence of alcohols, phenols, alkanes, carboxylic acids, aromatics, ketones, and alkyl halides compounds which shows major 
Table 4: FTIR peak values and functional groups of petroleum ether extract of Embelia ribes

\begin{tabular}{|c|c|c|c|c|c|c|}
\hline \multirow{2}{*}{$\begin{array}{l}\text { Serial } \\
\text { number }\end{array}$} & \multicolumn{6}{|c|}{ Functional groups of the active component in petroleum ether extract Embelia ribes } \\
\hline & $\begin{array}{l}\text { Stem peak } \\
\text { value }\end{array}$ & Functional group & Leaves peak value & Functional group & $\begin{array}{l}\text { Berries } \\
\text { peak value }\end{array}$ & Functional group \\
\hline 1 & 3749.9 & Phenols & 3364.21 & Phenols & 3307.32 & Alcohol, phenols \\
\hline 2 & 3649.62 & Amine, amide & 2957.3 & Alkane & 2921.63 & Alkanes \\
\hline 3 & 3309.25 & Alcohols, phenols, amines, amide & 2923.56 & Alkane & 2853.17 & Alkanes \\
\hline 4 & 2955.38 & Alkanes & 2854.13 & Alkanes & 1746.23 & Esters \\
\hline 5 & 2849.31 & Alkanes & 1705.73 & Aldehyde, ketone, ester & 1711.51 & Esters \\
\hline 6 & 1731.76 & Ketones, aldehyde & 1596.77 & $\begin{array}{l}\text { Primary amines, } \\
\text { aromatics }\end{array}$ & 1614.13 & Amino acid \\
\hline 7 & 1614.13 & Amino acid & 1456.96 & Alkanes, aromatics & 1461.78 & Alkanes, aromatics \\
\hline 8 & 1462.74 & Alkanes, aromatics & 1376.93 & Nitro compounds & 1327.75 & Nitro compounds \\
\hline 9 & 1376.93 & Alkane, Nitro compounds & 1158.04 & Alkyl halides & 1193.72 & Ether \\
\hline 10 & 1190.83 & Aliphatic amines & 838.883 & $\begin{array}{l}\text { Primary, secondary } \\
\text { amines }\end{array}$ & 709.676 & Aliphatic compound \\
\hline 11 & 1081.87 & Aliphatic amines & & & 521.65 & Alkyl halides \\
\hline
\end{tabular}

FTIR: Fourier transform infrared spectroscopy

peaks at $3370.19,2955.65,2925.68,2853.40,1739.72,1463.02$, and $506.57 / \mathrm{cm}$, respectively [20].

FTIR spectral analysis of plant parts such as flowers, leaves, stem, and roots of Aerva lanata showed the presence of characteristic functional groups of alcohols, phenols, alkanes, carboxylic acids, aldehydes, alkenes, nitro compounds, alcohols, carboxylic acids, esters, ethers, aliphatic amines, and alkyl halides compounds derivatives which were responsible for medicinal properties of the plant [19]. Similar type of analysis has been documented in Ichnocarpus frutescens [21] The methanol extract of Limonia acidissima fruit contained alcohols, phenols, alkanes, amino acids, $\alpha, \beta$-unsaturated esters, alkenes, nitro compounds, aromatics, aliphatic amines, carboxylic acid, alkenes, and alkyl halides compounds [22], and the ethanol extracts of Ipomoea obscura (L.) showed the presence of most of the secondary metabolites in the plant leaves [23]. Similarly, Cayratia trifolia plant stems ethanolic extract holds more phytochemical and bioactive compounds which were confirmed using FTIR [24]. The methanolic extract of fruit pulp of Feronia limonia shown the presence of phenolic, aromatic, and aliphatic functional group [25].

\section{CONCLUSION}

The results of the present study showed the presence of amino acids, amide, alkanes, alkenes, alkynes, aldehyde, ketones, fluorides, carboxylic acids, alcohols, esters, ethers, aromatics, aliphatic amines, p-substituted alcohols or phenols, disulfide, halogens, alkyl halides, and nitro compounds as functional group. It indicates the medicinal property of $E$. ribes, which can be utilized for various pharmaceutical purposes. Further advanced spectroscopic studies are needed to elucidate the structure and identification of active principles present in the E. ribes.

\section{ACKNOWLEDGMENTS}

The authors are thankful to Head, Department of Botany, Shivaji University, Kolhapur, for providing the necessary facilities and Dr. J. D. Patil, Department of Chemistry, Shivaji University, Kolhapur, for his help in FTIR spectrum analysis. VVK is thankful to UGC, New Delhi, for financial support under UGC-BSR Fellowship in Sciences for Students (No. F. 25-1/2013-14 (BSR)/7-163/2007(BSR)). We are also thankful to Karnataka State Biodiversity Board, India, for granting us permission to collect the plant material.

\section{REFERENCES}

1. Surewicz WK, Mantsch HH, Chapman D. Determination of protein secondary structure by Fourier transform infrared spectroscopy: A critical assessment. Biochemistry 1993;32(2):389-3.
2. McCann MC, Hammouri M, Wilson R, Belton P, Roberts K. Fourier transform infrared microspectroscopy is a new way to look at plant cell walls. Plant Physiol 1992;100:1940-7.

3. Yang J, Yen HE. Early salt stress effects on the changes in chemical composition in leaves of ice plant and Arabidopsis. A Fourier transform infrared spectroscopy study. Plant Physiol 2002;130(2):1032-42.

4. Ivanova DG, Singh BR. Nondestructive FTIR monitoring of leaf senescence and elicitin induced changes in plant leaves. Biopolymers 2003;72(2):79-85. Available from: http://www.onlinelibrary.com/ doi/10.1002/bip.10297/pdf.

5. Marimuthu M, Gurumoorthi P. Phytochemical screening and FTIR studies on wild and common south Indian legumes. Asian J Pharm Clin Res 2013;6(2):141-4.

6. Ashokkumar R, Ramaswamy M. Phytochemical screening by FTIR spectroscopic analysis of leaf extracts of selected Indian medicinal plants. Int J Curr Microbiol Appl Sci 2014;3(1):395-6.

7. Stehfest K, Toepel J, Wilhelm C. The application of micro-FTIR spectroscopy to analyze nutrient stress-related changes in biomass composition of phytoplankton algae. Plant Physiol Biochem 2005;43(7):717-26.

8. Muruganatham S, Anbalagan G, Ramamurthy N. FTIR and SEM-eds comparative analysis of medicinal plants. Eclipta alba HASSK and Eclipta prostrata Linn. Rom J Biophys 2009;19(4):285-94.

9. Ravikumar K, Ved DK. 100 Red Listed Medicinal Plants of Conservation Concern in South India. Bangalore, India: FRLHT; 2000. Available from: https://www.books.google.co.in/books/about/100_red listed medicinal plants of conse.html?id=EUQPAQAAMAAJ.

10. Mhaskar M, Joshi S, Chavan B, Joglekar A, Barve N, Patwardhan A Status of Embelia ribes Burm. f. an important medicinal species of commerce from northern Western Ghats of India. Curr Sci 2011;100(4):547-52.

11. Sivarajan VV, Balachandran I. Ayurvedic Drugs and Their Plant Sources. Oxford and IBH Pub., Co., Pvt., Ltd., India. 1994. p. 267-96. Available from: https://www.books.google.co.in/books/about/ Ayurvedic Durgs and their plant source.html?id=nQCmj2PO9gAC.

12. Gupta OP, Ali MM̄, Ray Ghatak BJ, Atal CK. Some pharmacological investigations of embelin and its semisynthetic derivatives. Indian J Physiol Pharmacol 1977;21(1):31-9.

13. Du YC, Wie JS. Study of vermifuges. I. Isolation of embelin from the fruit of Mugua-wha Embelia oblongifolia Hemsl.). Yao Xue Xue Bao 1963;10:578-80.

14. Dallacker F, Löhnert G. Derivatives of methylenedioxybenzene 35 . A novel synthesis of 3,6 dihydroxy-2-ethyl-1,4-benzoquinone, embelin, vilangin, rapanone, dihydromaesaquinone, bhogatin, spinulosin and oosporein. Chem Ber 1972;105(2):614-24.

15. Chitra M, Sukumar E, Suja V, Devi CS. Antitumor, anti-inflammatory and analgesic property of embelin, a plant product. Chemotherapy 1994;40(2):109-13.

16. Kim SW, Ban SH, Chung H, Cho S, Chung HJ, Choi PS, et al. Taxanomic discrimination of flowering plants by multivariate analysis of Fourier transform infrared spectroscopy data. Plant Cell Rep 2004:23:246-50.

17. Komal Kumar J, Devi Prasad AG. Identification and comparison of 
biomolecules in medicinal plants of Tephrosia tinctoria and Atylosia albicans by using FTIR. Rom J Biophys 2011;21(1):63-71.

18. Liu H, Sun S, Lv G, Chan KK. Study on Angelica and its differen extracts by Fourier transform infrared spectroscopy and twodimensional correlation IR spectroscopy. Spectrochim Acta Part A 2006;64:321-6

19. Yamunadevi M, Wesely EG, Johnson M. FTIR spectroscopic studies on Aerva lanata (L.) Juss. Ex Schult. Asian J Pharm Clin Res 2012;5(2):82-6.

20. Bobby MA, Wesely EG, Johnson M. FT-IR studies on the leaves of Albizia lebbeck Benth. Int J Pharm Pharm Sci 2012;4(3):293-6.

21. Thangarajan S, Paramasivam R, Chinthamony AR, Palanisamy CP, Velliyur KG. Element and functional group analysis of Ichnocarpus frutescens R. Br. (Apocynaceae). Int J Pharm Pharm Sci 2012;4(5):343-5.

22. Srinivasan P, Dineshbabu J, Manimekalai K, Priya DD. Spectroscopic analysis and antibacterial efficacy of bioactive compounds from Limonia acidissima $\mathrm{L}$. fruit extract against clinical pathogens. Int $\mathrm{J}$ Pharm Pharm Sci 2015;7(3):383-9.

23. Saravana PP, Gopalakrishnan VK. Phytochemical screening, functional groups and elemental analysis of leaf extract of Ipomoea obscura (L) ker-gawl. Int J Pharm Pharm Sci 2014;6(9):83-9.

24. Sundaram S, Palanisamy CP, Velliyur KG. Chromatographic and spectrophotometric analysis of bioactive compounds from Cayratia trifolia (L) stem. Int J Pharm Pharm Sci 2016;8(6):56-64.

25. Jayashree VH, Ramesh L. Isolation and identification of a flavone from fruit pulp of Feronia limonia. Int J Curr Pharm Res 2014;6(4):28-31. 